\title{
The archaeology of scattered wreck-sites: formation processes and shallow water archaeology in western Lake Huron
}

\author{
John M. O'Shea \\ Museum of Anthropology, University of Michigan, Ann Arbor, Michigan 48109-1079, USA
}

This paper explores the application of archaeological site formation theory to stranded wooden vessels and the scattered wreck-sites they produce. Shallow water wrecks and wreckage sites in the Au Sable Shores region of western Lake Huron are used to develop a preliminary classification of the processes operating on the breakup and deposition of wooden vessels.

(C) 2002 The Nautical Archaeology Society

Key words: shipwreck, Lake Huron, Great Lakes, site formation, scattered wreck

\section{Introduction}

$\mathbf{E}$ very wreck is unique. The site typically represents a single vessel, on a single voyage from a particular port, that succumbed to some specific condition or set of conditions at one particular time, which caused it to sink and be deposited in a one particular place. The sense of the unique is enhanced when there are historical accounts of the vessel, its fate, and its crew. This view of shipwrecks supports a general image of shipwreck-sites as unique 'time capsules' that provide an instantaneous, but inherently unique, snapshot of a single time in the past (Bass, 1983). This perspective is equivalent to what has been termed the 'Pompeii premise' (Binford, 1981); a view of the archaeological record as a frozen moment in time.

It is difficult, however, to apply such a perspective to most shallow water wrecks, particularly when the vessel has been broken up and scattered. Indeed, some underwater archaeologists have suggested that shallow water wreck-sites are not worth investigation, since they have so little coherent information content (Dumas, 1972: 3233; but see Tomalin et al., 2000). Ironically, such shallow water wrecks have much in common with conventional terrestrial archaeological sites.

Terrestrial sites are increasingly viewed not as a frozen moment in time, but rather as a palimpsest of distinct, short-term events and behaviour, created under the joint force of inten- tioned cultural activities and natural formation processes. In essence, each deposit or feature on a typical terrestrial site could be described in the same terms as a shipwreck. It is a unique event, on a specific historical trajectory of individual action and local circumstances, which results in a particular deposition of material remains within a specific spatial matrix. Yet all this uniqueness does not mean that the deposits are unrelated nor does it mean that they cannot be combined systematically with other observations to build up a more dynamic picture of human activity in the past. It is the role of archaeological theory to guide the archaeologist in understanding the deposit itself, and to determine how the deposit can appropriately be used to understand events and activities in the past.

Underwater research, perhaps more than even terrestrial archaeology, is characterized by an extensive but implicit and anecdotal understanding of the factors that affect sites, such as storms, waves, woodworm, looters, or reef formation. The implicit character of this understanding causes it to be applied inconsistently and further contributes to the illusion of site uniqueness. The need to develop a more systematic understanding of the archaeological record is not an exercise in theory for theory's sake. For the underwater archaeologist, it is rather the necessary foundation on which any historical or anthropological understanding of the vessel and its wreck must be based (Fontenoy, 1998). 
A ship, as a large, complex and expensive artefact (even a simple dugout canoe represents a major investment of time, labour, and materials), shares a number of characteristics with other complex, long use-life artefacts, such as house structures. It can be expected to retain information relating to its initial construction and place of origin, and to its life history of use and modification, as well as the evidence of its final loss or abandonment. Therefore, the processes of vessel construction, use, loss, deposition, and recovery should be understandable in terms of the body of archaeological theory that is subsumed under the heading 'formation theory' (Schiffer, 1987). The issue of formation processes looms particularly large when the focus of research shifts from the investigation of a single, intact wreck to a regional study, as in the Au Sable Shores project described below.

In essence, formation theory is designed to deal with two related archaeological problems: (1) how do materials pass from a systemic context, where they are part of an ongoing behavioural system, into a static archaeological context; and (2) what happens to these material remains and their spatial interrelationships between the time they are deposited and the time they are recovered by the archaeologist.

The first question relates to what can be termed depositional theory. How an item comes to be incorporated into the archaeological record has a major impact on the potential meaning that can be attached to it by the archaeologist. Was the item intentionally placed? Or discarded? Or lost? Did the deposit occur as a result of natural processes or human agency? Clearly, to answer questions of this kind we need to know something about the systemic context and the way material items were used and consumed prior to deposition.

The second question relates to postdepositional and recovery processes. Postdepositional theory is concerned with what happens once an object has left the systemic context. What portion is preserved (or not preserved)? How is the deposit later modified or redeposited? To what extent has scavenging or recycling of materials taken place? The natural elements of these questions are effectively taphonomic, while the human aspects may reflect the activity of the same or different cultural groups, at near or more distant points in time.

Archaeologists have increasingly realized the importance of recovery theory (Clarke, 1973).
Recovery theory is concerned with how the actual process of archaeological discovery and recovery can distort or bias the perception of the archaeological record. In terrestrial archaeology, an appreciation of recovery processes is reflected in the practice of random sampling in field survey, to ensure the sample of discovered sites is representative, and the use of screening during excavation to standardize recovery. For underwater research, an entire host of additional issues relating to human physiology and perception in an underwater environment must also be considered (Muckelroy, 1978: 182; van Tilburg, 1994).

\section{Shipwrecks as archaeological phenomena: the archaeological systematics of shipwreck-sites}

An overview of formation theory for shipwrecksites must necessarily extend from pre-deposition processes through to the archaeological recovery and analysis of remains from an underwater site. The goal of this overview is to provide a general sense of the framework or outline of the theoretical process, rather than to provide an exhaustive treatment of any of the particular aspects of theory. In the next section, based on recent work in the Great Lakes, some specific aspects of depositional and post-depositional theory for stranded wooden vessels will be offered. It should also be noted that many of the concepts drawn together here have already been suggested and employed in one guise or another in underwater research $^{[1]}$ so the effort here is directed more at showing how these different elements can be integrated into a single unified approach to understanding underwater archaeological deposits.

Prior to the wreck event itself, the vessel, its contents, and crew all operate within an ongoing systemic context. Souza refers to activities in this stage as 'pre-depositional processes' (1998: 47 48). These activities occur in the period immediately prior to the wreck event and reflect efforts by the crew to compensate for risky local conditions while the ship is in passage. These activities are sometimes referenced as part of the 'wrecking process' (Souza, 1993: 308) or simply as an aspect of the 'formation processes' (Murphy, 1993: 268269). In a strict sense, such operations are occurring within the systemic context and do not themselves result in archaeological deposition. They do, however, produce an imprint on the materials and spatial relationships that come to be 
manifested in the archaeological record. Souza's example is a case in point for understanding the circumstances of a given wreck.

Since all activities in the systemic context may pattern the material remains in the archaeological deposit, these pre-depositional processes can be viewed as part of a much broader range of activities and practices. The technique and style employed in construction, alterations and repairs experienced over the life of the vessel, the current use of the vessel, all as well as the immediate pre-wreck attitude of the vessel, all fall within this realm (Conlin, 1998). A consideration of these pre-depositional features can serve to highlight diverse classes of information that may be recoverable from the wreck-site.

It is in the consideration of such "predepositional' aspects of the vessel that the complementary role of historical research becomes most prominent. And as with the archaeological investigation, such historical investigations need to be pursued on a wide range of scales, from the global social history (Gould, 2000) to the minutiae of idiosyncratic nailing techniques of particular shipyards (McCarthy, 1996).

\section{Depositional processes}

Depositional theory should account for the character and circumstances of the wrecking and for any other factors that are relevant to the initial creation of the archaeological deposit. There are, obviously, many ways that these depositional factors might be categorized. One approach is to begin with a classification of wreck types, since this should have important implications for the form and character of the resulting deposit (Thompson, 2000: 34). For example, in the Annual Reports of the United States Life Saving Service (1876-1914) wrecks are divided into the categories of Foundering, Stranding, and Other. As a starting point, the contrast between vessels that have foundered and stranded seems quite useful since it implies very different trajectories for the final disposition of the wreck. A vessel that founders is usually in deeper water and will tend to arrive at the bottom in a more or less intact condition. By contrast, a vessel that is stranded is much more likely to be deposited in a broken up condition. One can easily make the same characterization for the different categories of circumstances subsumed under the rubric of 'other causes', such as wrecking due to fire, collision, hostile action, or scuttling. The systematics of scuttled vessels presents its own interesting complexities, since it would be important to distinguish intentional abandonment of a vessel from the use of scuttling as an emergency procedure to save the vessel for subsequent salvage (which of course failed, since the vessel remained on the seabed for archaeological investigation).

Within each category of depositional process, the task of the nautical archaeologist is twofold: (1) to determine the unique characteristics of a given depositional pathway that would enable one to identify the process from the resulting wreckage; and (2) to ascertain what other aspects of site formation can be inferred once the specific depositional pathway has been established. This is the basic dialectic or interplay between observation and theory that constitutes the application of formation theory in archaeology (Muckelroy, 1978: 189-190). How does one know that this vessel was intentionally scuttled? And knowing that it was intentionally scuttled, what else can be inferred about the character and condition of the vessel at the time of deposition?

Environmental conditions at the time and place of the wreck represent another relevant set of depositional processes. Clearly, if the local weather and water conditions are known, or can be determined, a great deal can be predicted regarding the expected aspect and condition of the wreck, and the distribution of wreckage. Conversely, if these factors are not known $a$ priori, it may be possible to infer them from the condition of the wreck. There may be other depositional factors that are worth considering, such as the suddenness of the sinking, or whether the loss of the vessel was controlled or catastrophic.

\section{Post-depositional processes}

Nautical archaeologists have devoted considerable thought to the changes that wrecks undergo once they are deposited (Gould, 2000: 8-9). Much of this effort has been anecdotal and site specific, but there have been efforts to systematize these processes. Muckelroy's study of the Kennemerland wreck is a pioneering example (1975). In this case, Muckelroy employed cluster analysis to identify sets of artefacts that had similar distributional properties, either as a result of their original position on site or as a result of their being acted upon by similar forces in the underwater environment. Muckelroy identifies two classes of postdepositional processes, which he terms 'extracting 
filters' and 'scrambling devices' (1978: 165-182). Following this usage, extracting filters are processes that remove material from the site so that they are not present for discovery. Scrambling devices, by contrast, are processes that move materials from their primary context. One problem with the concept of scrambling devices is that it implies a randomizing or pattern diminishing effect. Yet, many natural and cultural processes that act on shipwrecks in situ have the effect of introducing new organization or pattern, such as the simple process of size sorting (Murphy, 1990: 53). Similarly, there are a number of factors that can produce an artificial concentration of related, or unrelated, cultural materials at the site of the wreck, in effect, providing the inverse to Muckelroy's extracting filters. An example is the case of the Adelaar (Martin \& Long, 1975; Muckelroy, 1978: 180). Any systematic treatment of post-depositional factors must account not just for the weakening of patterns and associations, but also for the creation of new and potentially spurious patterning.

Given the great number of processes and factors that can exert an influence on wrecks once they have been deposited, it is difficult to develop a classification that is both simple and yet retains analytical value. One useful starting point may be to distinguish those processes that are the result of direct human intervention as opposed to natural geophysical and biological processes (McCarthy, 2000: 53).

Direct human intervention can take a variety of forms, ranging from salvage and scavenging, to intentional breakup of the wreck, to new construction and stabilization. In many cases, this intervention is intentional and is oriented towards achieving an identifiable end, whether to clear a channel for navigation or to remove artefacts from a wreck for personal profit. Yet there will be other instances where the disturbance is inadvertent, as when a fisherman's net is snagged or when a developer drives the pilings for a new condo project through a buried wreck. In all of these cases, however, the likely biasing effect on the archaeological record can be predicted and controlled, at least analytically. Direct human intervention can also have interesting temporal and cultural dimensions. Is the intervention the result of actions by the vessel's own crew, by contemporary salvagers, or other, possibly indigenous or unrelated, cultures? Equally, is the activity occurring near in time to the wreck or at a long time removed? Here, again, the interplay between observation and theory leads the archaeologist both to seek diagnostic attributes associated with differing kinds of activities and to make inferences about other aspects of the wreck that may not be visible at the site.

There are so many potential geophysical and biological processes that can affect or alter a shipwreck-site that any effort to summarize them here would be futile. These processes are perhaps best thought of as the 'ecology' of the wreck locality (Muckleroy, 1978: 181). This definition would include all of those factors (climatological, geological, biological) that may affect the site. While these processes are general in nature, their effects and significance will be extremely local in character. They may also be variable, as in the contrast between normal bottom conditions and conditions that occur during storms (Murphy \& Jonsson, 1993). It should also be anticipated that the wreck itself will have an impact on the site ecology, as a sediment trap, a habitat for marine life, or even as a source of toxic materials (LaValle et al., 1999). These processes will have a major effect on what remains of the wreck, how it is distributed, and indeed, whether the wreck is in fact discovered. Yet as natural processes they are largely predictable and their likely effects can be anticipated.

\section{Recovery processes}

The final step in the chain of reasoning is recovery theory. Included under this heading would be how a given site comes to be discovered, and what from the wreck's archaeological deposit comes to be recorded and recovered for analysis. Each of these questions also implies a converse-what deposits are not discovered, and what remains are not recovered or recorded? Questions of this kind are particularly significant when the analysis stage of research begins, or when the analyst seeks to make comparisons or to draw conclusions based on a body of data. Is a particular search technique more likely to find one kind of wreck-site than other types? Are wrecks in shallow water more likely to be recorded than wrecks in deep water? Was the recovery of artefacts controlled (was the deposit screened, for example)? To what extent has the site already been scavenged or collected? These are precisely the same questions that an archaeologist working on land must ask before any meaningful analysis can be done. 


\section{Theory and systematics}

In this brief overview of archaeological formation processes and underwater sites, one might well ask, so where is the theory? What has been outlined is more a structure for organizing inquiry and data, than an explanatory or predictive theory. In fact, the presentation has been more a discussion of meta-theory (or a theory of theory) than specific theory itself. The meta-theory highlights the blanks that the investigator must fill in with substantive information relevant to the particular site's circumstances. This substantive theory will come from a number of related disciplines: oceanography, geology, zoology, physics which must be adapted to the specific conditions of the particular wreck under investigation. The usefulness of formation theory, for both the terrestrial and nautical archaeologist, comes from the systematic structure it imposes. In effect, it provides a checklist of conditions that must be satisfied to ensure that the information recovered can be used as evidence to understand past activities. Formation theory also provides a structure for applying information that is gained from a wreck-site. Nowhere is this systematic structure more useful than in cases where formation theory enables the archaeologist to work back and forth between the written records and the archaeological deposit, amplifying both.

\section{Identifying formation processes for scattered wrecks: the Au Sable Shore region of western Lake Huron}

The study of scattered wrecks is a far cry from the popular image of shipwreck archaeology, with its focus on the discovery or identification of a single intact vessel. Instead of the single vessel, research is focused on a region in which wrecks occurred. Wrecked vessels and wreckage within the area are not viewed in isolation, but are viewed instead as an aspect of the regional environment. An important goal of the Au Sable Shores survey was the discovery and identification of vessels that had been lost in the area. But the survey was also intended to investigate how the archaeological deposits came to be in their present locations, and to identify systematic elements in these distributional processes that might be applied to secure the future protection and preservation of the wreck-sites. The following sections present an initial classification of the systematics of stranded

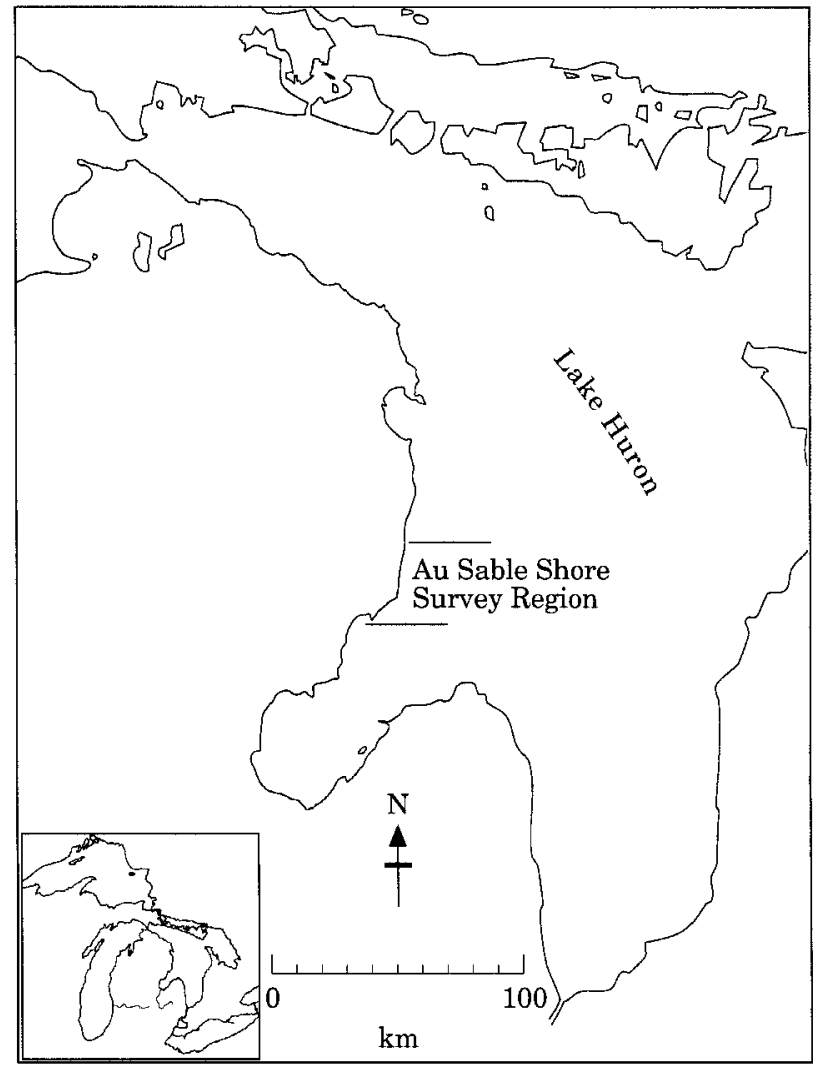

Figure 1. The Au Sable Shores region, western Lake Huron. (Drawing: J. M. O'Shea)

wooden vessels in the Great Lakes. While the discussion is cast in terms of the research in western Lake Huron, information is drawn from a much wider region and the results will also, it is hoped, have more general applicability.

\section{Background}

The Great Lakes region in North America was an area of intensive water-based commerce and traffic during the 19th and early 20th centuries (Mansfield, 1899). Lake vessels were responsible for moving major bulk goods, such as coal, timber, grain, and ores throughout the Midwest. Prior to the coming of the railroads, they were the primary source of food, manufactured goods, and transport for the peoples living around the lakes. Vessels during this time were overwhelmingly of wood. They comprised wind-driven schooners, steam-driven propellers and sidewheelers, and towed barges (often modified schooners) (Thompson, 2000). The Au Sable Shores project ${ }^{[2]}$ is concerned with the wrecks of such vessels in western Lake Huron within a 
Table 1. Near shore wrecks in the Au Sable shores region of Lake Huron

\begin{tabular}{|c|c|c|c|c|c|c|c|}
\hline Name & Commissioned & Sunk & Type & Capacity & Cargo & Loss type & Comments \\
\hline May Queen & 1855 & 1859 & Schooner & 246 tons & Wheat and barley & Stranding & \\
\hline Water Witch & 1861 & 1863 & Bulk Freight Propeller & 458 tons & Copper, passengers & Foundered & \\
\hline Eureka & & 1869 & Sloop & 10 tons & & & \\
\hline Summit & 1856 & 1872 & Schooner & 226 tons & Iron Ore & Stranding & Salvaged \\
\hline Table Rock & 1853 & 1872 & Schooner & 179 tons & Lumber & Stranding & \\
\hline White Squall & 1852 & 1872 & Schooner & 241 tons & & Collision & \\
\hline Ocean & & 1873 & Barge & & & Foundered & \\
\hline Wayne & 1848 & 1875 & Schooner & 80 tons & & Stranding & \\
\hline Athenian & 1856 & 1880 & Schooner & 372 tons & Lumber & Stranding & \\
\hline Stranger & 1872 & 1880 & Schooner & 16 tons & & Stranding & \\
\hline John Prindiville & 1867 & 1882 & Freight-Propeller/Tug & 270 tons & Ballast & Stranding & \\
\hline James C. Harrison & 1870 & 1885 & Schooner & 518 tons & Iron Ore & Stranding & Salvaged? \\
\hline Susan Ward & 1863 & 1885 & Barge & 365 tons & Lumber & Stranding & Refloated? \\
\hline Ferguson & & 1886 & Schooner-Barge & & & Foundered & \\
\hline George Hand & 1868 & 1888 & Tug & 25 tons & None & Fire & \\
\hline Jane Mason & 1880 & 1889 & Schooner & 33 tons & Bricks & Stranding & \\
\hline Mears & 1869 & 1889 & Schooner-Barge & 429 tons & Lumber & Stranding & Located? \\
\hline Midnight & 1856 & 1889 & Schooner-Barge & 288 tons & Lumber & Stranding & \\
\hline Sea Gull & 1864 & 1890 & Steam-barge & 289 tons & Ice & Fire & \\
\hline John Shaw & 1885 & 1894 & Schooner & 928 tons & Coal & Stranding & Salvaged? \\
\hline Volunteer & 1889 & 1896 & Schooner & 31 tons & Lumber & Stranding & \\
\hline George Steele & 1855 & 1898 & Schooner & 271 tons & Lumber & Stranding & \\
\hline Baltimore & 1881 & 1901 & Bulk Freight Propeller & 1160 tons & Coal & Stranding & Located \\
\hline Thomas $P$ Sheldon & 1871 & 1901 & Schooner & 669 tons & & Collision & Refloated? \\
\hline Mary E. Pierce & 1871 & 1906 & Tug & 22 tons & None & Stranding & \\
\hline Wawanosh & 1876 & 1906 & Schooner & 370 tons & Lumber & Stranding & \\
\hline Andrew McLean & 1890 & 1916 & Tug & 24 tons & & Foundered & \\
\hline Goshawk & 1866 & 1920 & Schooner-Barge & 550 tons & Lumber & Foundered & Located \\
\hline Owen & 1881 & 1921 & Tug & 44 tons & None & Fire & \\
\hline Linden & 1895 & 1923 & Bulk Freight Propeller & 894 tons & Ballast & Fire & Removed \\
\hline Langell Boys & 1890 & 1931 & Bulk Freight Propeller & 387 tons & Ballast & Fire & \\
\hline Hercules & 1904 & 1932 & Dredge & 559 tons & None & & \\
\hline Dudley & 1926 & 1934 & Dredge & 95 tons & None & Foundered & \\
\hline
\end{tabular}

$38 \mathrm{~km}$ zone between Tawas Bay and the Au Sable River (Fig. 1). This is an area of relatively shallow coastal water and sandy seabed that lies between the notorious wreck zones at Point aux Barques and Thunder Bay. While Tawas Bay was the principal harbour of refuge in this portion of the lake, vessels, particularly those that were windpowered, often ran aground here during easterly storms. Given cooperative weather, most vessels in this predicament were refloated and saved, but in the case of violent weather, stranded ships were rapidly broken up by the waves and lost. Table 1 summarizes the vessels that are currently thought to have been wrecked and actually lost to stranding in this region. Vessels that foundered in the deeper waters of Lake Huron are not included in this list.

The unusually low lake levels of 1999-2001 provided a unique opportunity to investigate the distribution of the near-shore wrecks in the region. The aim of the research has been to identify the wreck-sites and wreckage along the near-shore region and to link these finds to specific vessels. Shallow water survey has been conducted both to identify areas of major wreckage concentration, and to document the surviving vessel wreckage. The research has also included the search of contemporary accounts of vessel loss and an analysis of historic maps to chart the rapidly changing shape of the near-shore region.

As can readily be imagined, the archaeological investigation of vessels that have been stranded and broken up for a century or more presents formidable problems of interpretation and analysis. Indeed, it is because of this complexity, that the understanding of formation processes is so critical. The discussion that follows summarizes the principal depositional and post-depositional 


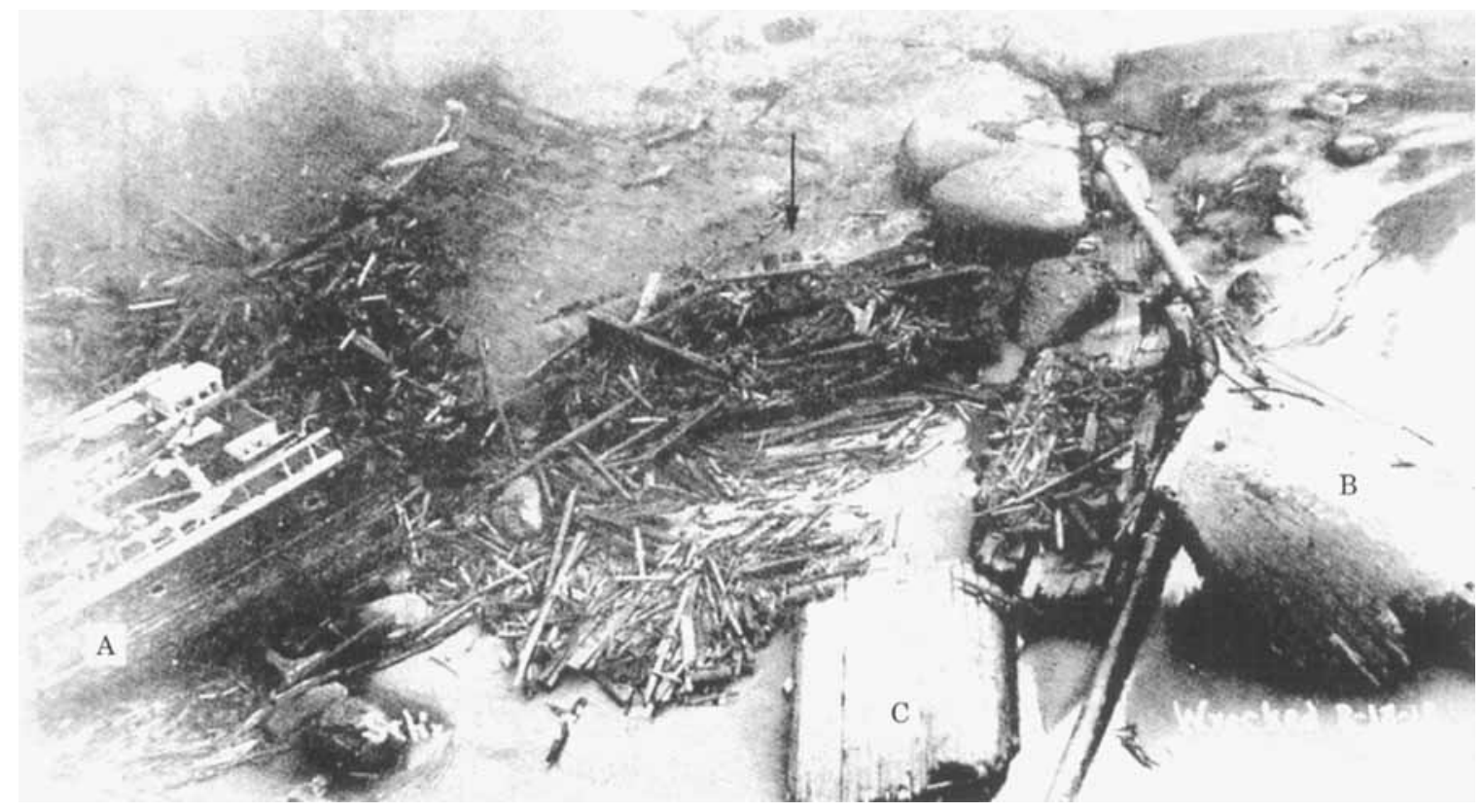

Figure 2. The wrecked schooner Advent, Coos Bay, Oregon, 1913. Letters A, B, and C mark the aft, fore, and side planking of the vessel. The arrow marks the broken ends of the lower frames. (Photo: courtesy James A. Gibson.)

processes that have been identified during the course of the Au Sable Shores research.

\section{Wreck creation: depositional processes}

The great majority of the wrecks in the Au Sable Shores region represent strandings (Table 1), although for several vessels the proximate cause for loss was fire. Yet, even when fire was the cause, the burning vessels either drifted, or were towed, into shallows where they subsequently grounded and broke up. However, the very first issue that must be assessed is whether a given vessel that was reported as stranded was in fact lost. Since the lake bottom is sand, vessels were often refloated or salvaged, with minimal damage. Indeed, captains occasionally scuttled their vessels in shallow water as a way of protecting them from severe weather. In the case of true losses due to strandings, the vessels typically were broken up by wind and wave action, as they were held fast to the bottom. This may occur as a single event, or it may occur in stages, with the vessel first being stranded, and then being broken up by a subsequent storm. Clearly, if there is an interval, it is much more likely that portions of the vessel and its cargo will be salvaged.

A central concern for the archaeology of scattered wrecks is the manner in which a wooden vessel breaks up once stranded. While there has yet to be a systematic study of this process for stranded wooden vessels, some regular elements can be offered based on anecdotal accounts and practical considerations.

A striking visual example of vessel breakup is provided in a contemporary photo of the Advent, a 431-ton schooner wrecked on the Coos Bay bar, Oregon, in February 1913 (Gibbs, 1986: 82) (Fig. 2 ). While this is not a Great Lakes vessel, its size and the circumstances of loss make it comparable to strandings in the Great Lakes. The vessel ran aground while crossing the bar, and was subsequently broken up by waves. Inspection of this photograph reveals the major components of a broken vessel. To the left, the aft portion of the vessel is intact [A]. To the right, the bow is similarly visible $[\mathrm{B}]$. In the centre foreground is a large section of planking [C], which extends from the gunwales to the turn of the bilge. This segment of planking presumably contains the upper futtocks of the vessel's frames, but does not appear to retain much if any of the decking. Immediately to the right of the planking is a segment of the fore interior beams and decking. In the centre of the photo, just above the mass of loose timbers, can be seen the broken ends of the lower frame elements of the vessel [arrow]. These are particularly significant insofar as they suggest 
that the keel assembly and bilge remain intact and buried beneath the sand. Finally, surrounding these largely intact portions of the vessel is a cloud of loose timber and other debris.

In viewing a photo such as this, the archaeological questions are obvious; what comes to be deposited and where? Certainly some systematic elements can be suggested. For example, the loose timbers and associated wreckage can be expected to be carried by the water from the wreck-site and scattered widely. This distribution ought to reflect both the normal water currents in the locality and the specific weather conditions associated with the wreck, as when wreckage is tossed high up on a beach during storms or high water. At the other end of the spectrum, it appears that the most stable portion of the wreck might be the keel assembly and bilge, which is already buried in the sand and which would not be expected to move unless the sea bottom itself were to be exposed. As such, the loose timbers may be expected to provide the most extensive evidence of the wreck, but to have the least spatial fidelity to the wreck-site, while the keel assembly should have the closest spatial association to the actual wreck-site, but typically with the lowest visibility. These expectations are not qualitatively different from those for deep-water wrecks except perhaps for the quantity of loose material and the distance it travels.

This characterization of the loose wreckage is certainly in accord with 19th-century accounts of Great Lakes wrecks, where often the first evidence of a marine disaster was the appearance of floating debris along the lakeshore. A good local example of this scattering process is provided by the wreck and wreckage from the steam barge $D$. M. Wilson. ${ }^{[3]}$ The Wilson foundered in a northerly gale about $3 \mathrm{~km}$ NNE of the light at Thunder Bay on 27 October, 1894 (Swayze, 2001). The vessel apparently was broken up during a second, northerly storm on 10 November. Quantities of wreckage washed ashore between $\mathrm{Au}$ Sable Point and Tawas Point, nearly $160 \mathrm{~km}$ to the south. The character of the wreckage that came ashore is recorded in the weekly Iosco County Gazette, published in East Tawas on 17 November, 1894:

What was evidently a large steam barge has foundered off Sable, her hull and deck parting. A terrible northern storm and snow raged during the night she was wrecked. The boat's deck is broken in, and several pieces of the pilothouse is gone. The hurricane deck and the rail forward of the pilot house were washed up in one place, the after hurricane deck with the whistle pipe, wire and whistle in another place and the port bulwark and parts of the main deck in still another place ... Most of the wreckage was washed ashore 3 miles south of Fish Point and 5 miles from East Tawas. About 4,000 cedar ties and a lot of timber also came ashore.

In this instance, not only light debris but also large segments of the vessel were rapidly transported and deposited a significant distance from the wreck-site.

A more detailed, although tragic, example is provided by the wreck of the wooden steamer Baltimore, which ran aground in a storm and broke up just south of Oscoda on Lake Huron's western shore in 1901 (Ferris, 1999). The Baltimore was a $201 \mathrm{ft}(61 \mathrm{~m})$ wooden steamer with a rated capacity of 1160 tons. The vessel ran aground while attempting to reach Tawas Bay during a severe northeasterly storm on 25 May, and wreckage from it was scattered widely. A published statement by the two survivors describing the vessel's final break-up fits well with the previous image of the Advent:

... She labored and pounded on the bottom for about two hours after this when she began to go to pieces, and finally broke in two. Her rails broke on both sides just aft of the forward house and as she began to split in two, we could see that many of her beams had started and pulled loose so that she was also breaking in two athwartships.... When we left the vessel she had practically broken all to pieces. From the morning of the wreck until noon May 27, Deponent Murphy and others patrolled the beach and found it strewn with great quantities of wreckage from the vessel for a distance of eighteen miles south of Tawas. (Marine Review, No. 22, 1901: 16)

Here, as with the Advent, a stranded vessel comes apart at the seams, and breaks into freefloating fore, aft, and side portions, along with an immobile bilge and keel. There is also a vivid sense of the floating 'cloud' of loose wreckage that is subsequently distributed over great distances down lake from the wreck-site.

In the case of the Baltimore, along with the great quantities of wreckage went the bodies of 12 crew, and it is through their identification that it is possible to trace positively the distantly scattered wreckage to the Baltimore. The distribution of recovered crew bodies and wreckage is shown in Fig. 3.

What is most striking about this map is how far and how rapidly the debris travelled from the wreck-site. The first identified body was found amid wreckage at Point Lookout on 26 May, one 


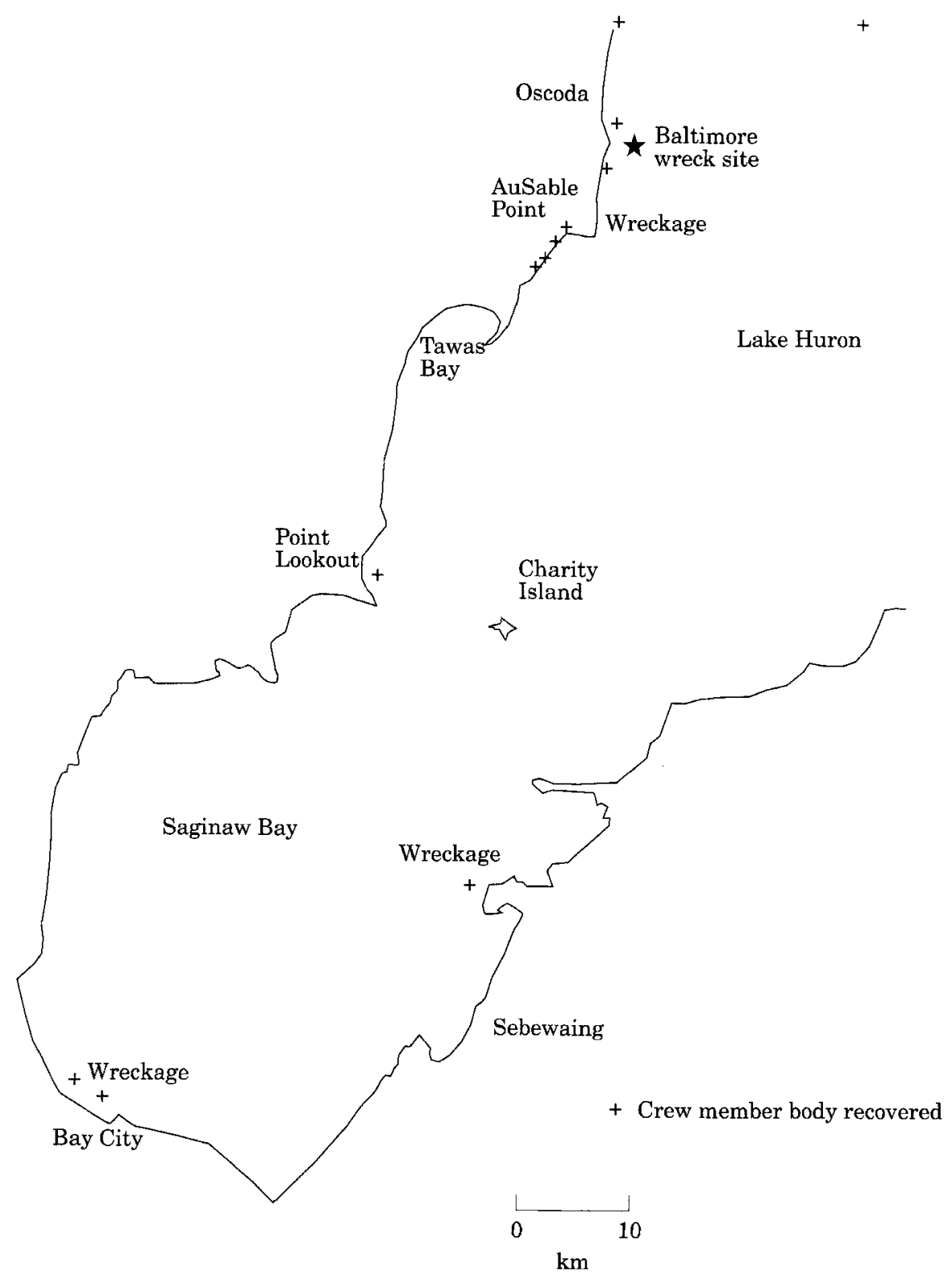

Figure 3. Distribution of wreckage and recovered bodies from the wrecked steamer Baltimore, 1901. (Drawing: J. M. O'Shea)

day after the storm and some $50 \mathrm{~km}$ distant from the wreck-site. On 27 May, a second body was recovered along with large pieces of wreckage near Bay City, $100 \mathrm{~km}$ from the wreck-site, and on 2 June, a week after the wreck, a body and substantial portions of wreckage, including a segment of the stern and furnishings, was found on Maisou Island on the opposite side of Saginaw Bay $(65 \mathrm{~km}$ direct but $200 \mathrm{~km}$ via shore current circulation). As regards the breakup of the vessel and its dispersal, it is also interesting to note that the two survivors of the wreck were found off Tawas Point lashed to a $3 \times 4 \mathrm{~m}$ segment of the promenade deck. The fisherman who rescued the survivors reported that the decking was drifting at a rate in excess of eight miles per hour $(13 \mathrm{~km} / \mathrm{h})$ (Ottawa Point Life Saving Station Log, 24 May, 1901).

Based on these examples, loose timbers and wreckage should be distributed widely from a wreck-site, moving in the direction of prevailing currents and winds. A locality that has 
experienced a number of wrecks, therefore, may present a broad scattering of planking and timbers, with concentrations of wreckage more likely reflecting debris 'traps' rather than necessarily indicating the location of true wreck-sites.

The distribution of wreckage from the Baltimore and the Wilson touches on a second systematic element in the deposition of broken wrecks. As was seen in the photo of the Advent, large portions of a vessel may remain intact during its initial breakup and, as the Baltimore and Wilson accounts indicate, these large segments might be scattered widely, and in much the same manner as smaller pieces of wreckage. This observation is borne out in numerous other anecdotal accounts.

On reflection, this occurrence is not difficult to understand. As the stranded vessel breaks up, these large buoyant segments with a high degree of structural integrity break free from the constraint of the bottom and drift with the prevailing current and winds. It would be expected that some portions would move into shallow water near the wreck-site and be beached, while other portions drift away from the site. It might also be expected, given their large surface area, that they may be affected more by winds in this process than would individual timbers. These vessel fragments would drift either until they are beached, or until they lose their buoyancy and sink to the lake bottom. The significant point, from the perspective of archaeological site formation, is that even large and intact segments of broken vessels may move great distances from the wreck-site.

Arguably, the least mobile portion of a stranded and broken vessel is the bilge and keel assembly. This is the heaviest and least buoyant portion of the boat, and is the part that in most cases will be firmly embedded in the lake bottom. Heavy deposits of ballast and cargo may also overlie it. Given these factors, and its size, the keel and bilge assembly is the least likely portion of the vessel to move from the initial wreck-site and may therefore be the best indicator of the actual wreck location. Unfortunately, these same factors make the keel assembly the most difficult element to locate visually (although its linear shape and the extensive fastenings used in the construction of the keel assembly make it a good target for location via remote sensing). This is not to say, however, that keels or bilges never move, but that movement will more likely be the result of postdepositional changes in the lake bottom, rather than to the initial conditions of deposition.
The rudder assembly represents another category of heavy and relatively immobile vessel element, although it shares much in common with other portions of the midline structure. Rudders were typically constructed of massive timbers that were held together by heavy metal fasteners and metal strapping. In most instances the rudder will be detached and deposited as a structural unit and, given its weight, it would be expected to sink rapidly to the bottom and be deposited in situ. Lying flat on the lake bottom, the rudder may rapidly be covered by sediment and completely obscured from view. As such, the rudder, like the keel and bilge assemblies, may be expected to retain a close fidelity to the original wreck-site. It will also have a relatively low visibility profile although the quantity of metal fastenings may facilitate the use of remote sensing techniques for its discovery.

While intact rudders are readily identifiable as ship wreckage, their great weight and size mitigates against their removal from wreck-sites. Unlike other central portions of the vessel, though, rudders often were lost from vessels that were not wrecked. So while rudders can be expected to remain at the site of loss, they may be found at locations that are not vessel wreck-sites.

Heavy machinery and furnishings from a stranded vessel may behave in a similar manner. Heavy machinery can be expected, in most cases, to break free from moorings and to sink quickly to the lake bottom at the site of the wreck. These may include anchors (deployed or undeployed), capstans, windlasses, cannon (if armed), engines, boilers and other metal appliances. Smaller fittings, however, may float off with their attached timbers. In any event, large metal pieces should be deposited at the immediate wreck-site. Here again, though, is an instance where the site of initial deposition may be quite different from the site of eventual recovery, depending on a variety of post-depositional processes.

Cargo in the hold or on the deck of a vessel presents another interesting category of deposit. Heavy materials will sink rapidly to the bottom, and may also pin large portions of the vessel to the bottom, while lighter materials will float away once the holds are broken open. In the Great Lakes, the most common cargos were ore (heavy), coal (intermediate), and lumber and grain (light) (Table 2). On stranding, vessels carrying ore were pinned to the bottom and the cargo tended either to stay in the intact hold, or to spill out on the lake bottom once the holds were broken. Such 
Table 2. Great Lakes vessel cargo deposition and post-deposition potentials

\begin{tabular}{|c|c|c|c|c|}
\hline Cargo type & $\begin{array}{c}\text { Common Great } \\
\text { Lakes cargos }\end{array}$ & $\begin{array}{l}\text { Depositional } \\
\text { potential }\end{array}$ & $\begin{array}{l}\text { Post-depositional } \\
\text { movement potential }\end{array}$ & $\begin{array}{l}\text { Salvage } \\
\text { potential }\end{array}$ \\
\hline Heavy & Ore, Stone, Brick & High & Low & High \\
\hline Intermediate & Coal & High & High & High/Low* \\
\hline Light & Wood, Grain & Low & High & High/Low* \\
\hline
\end{tabular}

*Potential for salvage is high immediately after stranding, but becomes low once vessel has gone to pieces.

cargo will resist movement from natural forces. On the other hand, ores are the cargos that were most likely to be salvaged from the vessel, both immediately after stranding (when a lighter might be used to unload the vessel in an effort to float the ship, and to save the valuable cargo) or later when salvagers sought lost wrecks. Lumber, which often was piled high on vessel decks or towed in great rafts, was typically scattered during the wrecking process, and was recovered with difficulty from the lakeshore and the open lake. Little would remain in the vicinity of the wrecksite itself. Coal presents a more interesting problem. Coal, like ores, would often be removed from the stranded vessel during recovery efforts, but there was less economic interest in salvaging it once the vessel broke up. In such a situation, the coal would sink to the bottom, but then be transported by underwater currents, presumably undergoing continuous mechanical breakdown into progressively smaller sized chunks. As such, coal might be expected to have an initial distribution near the site of the wreck and then be transported progressively farther way. The size of coal chunks might be expected to decrease over exposure time, and the exposed outer surface of the material should show progressive evidence of weathering.

To summarize briefly, as the name implies, at scattered wreck-sites, vessels are broken up into larger and smaller pieces, which may then drift substantial distances from their point of origin. The large size of a vessel fragment does not preclude it from being deposited at a great distance from the initial wreck-site (Reedy, 1991: 53). The most likely portions of a vessel to be deposited in the immediate vicinity of the wrecksite are (1) the keel and bilge assembly of the vessel, and (2) heavy machinery and other nonbuoyant items and cargo. As such, only the latter two classes of items can provide reliable evidence for the original location of a wreck.
Wreck-site alteration: post-depositional processes

Post-depositional processes, both natural and human, can further alter the location and condition of scattered wreck remains. These varied processes work on a number of different time scales, but most have relatively predictable effects. As previously noted, post-depositional processes associated with human agency can be summarized under the terms salvaging, scavenging, and intentional or unintentional scattering.

Salvage efforts were common in the Great Lakes and elsewhere, particularly when the vessel retained some structural integrity. Even in cases when the vessel could not be recovered, it was economical to salvage not only valuable cargo and machinery, such as boilers and engines, but also anchors, rigging, and even sail cloth (Souza, 1998: 43-45). The relatively shallow depth of most strandings made salvage a particularly viable possibility. In some cases, strandings also provided the opportunity for salvage efforts to occur before the final breakup of the vessel. As such, it is likely that items, particularly items of high economic and reuse value, will be removed from the wreck-site whenever conditions permitted.

Scavenging, by contrast, is the removal of materials not intended for direct reuse. Scavenging may be contemporary or much later in time, and may take myriad forms. The removal of copper plates from the bottoms of British vessels by Native Americans on the Northwest Coast for the manufacture of tools and ritual objects is one example, the theft of vessel bells, nameplates and furnishings for decorations or the removal of timbers for furniture or curiosity are others. Scavenging, like salvage, results in the removal of materials from the site of deposition, which may or may not be the original wreck-site. Perhaps more than salvage, scavenging removes materials from the site that directly affect vessel identification and dating, and it is for this reason 
that the looting of wreck-sites is particularly regrettable. Finally, casual scavenging or collecting may also result in the creation of new concentrations of debris, as scavenged materials become incorporated into 'yard' or shore collections.

Not surprisingly, a number of post-depositional processes result in a further scattering of wreck remains. This can occur as an intentional outcome of human action, as when wrecks are blown up to ensure the safety of navigation, or unintentionally when they are unexpectedly encountered during shore modification activities, such as dredging or building. On a smaller scale, it can occur as an outcome of activities such as fishing, cable laying, or later vessel strandings. In the Great Lakes, the scattered wrecks resulting from coastal strandings did not commonly require active removal for navigational purposes; indeed, some strandings represent the towing of a hulk out of a navigation area with the intent of stranding it harmlessly in the shallows, as was the case with the schoonerbarge Thomas P. Sheldon (Annual Report of the United States Life Saving Service, 1902: 67). The main result of intentioned scattering would be to reduce large, intact portions of the vessel to a smaller size, which in turn would free them from their attachment to the lake bottom and permit them to drift as previously described.

The unintentional scattering of the wreck-site as a result of shoreline development can have a devastating impact on archaeological deposits, since it uncovers and scatters wrecks that have already been buried and stabilized. Obviously, the nature of the disturbance will determine whether the wreck-site is simply scattered or whether major portions of the wreck are removed permanently from the record, as in dredging.

As mentioned previously, there are a large number of natural processes that may affect the wreck-site. Of particular importance to the present discussion of Lake Huron is the ongoing process of shoreline and lake bottom remodelling that is associated with the recurved spit features of Tawas and Au Sable Points (Wadsworth, 1975; Meadows, 2000). These spits exist in a very active shore and near-shore environment, and have witnessed a repeating cycle of aggradation and scouring of the near-shore lake bottom. This process results in the periodic exposure and reburial of wreckage and debris. During the scouring phase, previously buried debris is exposed on the lake bottom, where it becomes vulnerable to deterioration, movement, and scavenging. The settling of heavier debris and artefacts during these scouring episodes also results in the accumulation and mixing of materials of differing ages on the immobile lake bottom substrate. During the subsequent aggradation phase, the materials that have accumulated on the bottom are reburied as a lag deposit beneath a thick layer of sand. Depending on the stage and the speed of the process, the location may be incorporated into the accumulating spit and eventually be found on or beneath dry land.

Survey in the Au Sable Shore area of Lake Huron provided several examples of the predictable character of these geological and hydrological processes. One is a keel and keelson assembly that was recorded to the east of Au Sable Point in the spring of 1999. The keel assembly became exposed in about $1 \mathrm{~m}$ of water as the point migrated in a southwesterly direction. As Lake Huron experienced its normal seasonal drop in water level into the autumn, progressively more of the keel assembly was exposed and, during the winter, the upper surface was above the ice. Yet by the following March, the wreck was completely buried beneath the sand, and was now located some 3 to $6 \mathrm{~m}$ inland from the lakeshore. A severe easterly storm in May reclaimed much of the newly created shore, and re-exposed a small portion of the keel assembly on the immediate shoreline. By August, 2000, the keelson was back beneath a half metre of water, and roughly $6 \mathrm{~m}$ beyond the shore. So in the space of little more than a year, the wreck was exposed, buried, re-exposed, re-submerged, and currently is in process of being buried once more. While it did undergo major damage and deterioration due to exposure during this period, the wreckage did not move, although its location relative to the modern shoreline changed.

The debris-concentrating effect of specific shore features can be documented on a number of spatial scales. At a macro-scale, the effect is clearly illustrated by plotting the location of debris encountered during the near shore survey. Figure 4 represents the Au Sable Shore region from the mouth of the Au Sable River to Tawas Point, and indicates the location of all modified timber observed during survey in May of 2001. (The western half of Tawas Bay was not surveyed during the 2001 season.) The bulk of modern timber is treated lumber from sea walls, while the vessel timbers derive from wrecks with an average age of more than 100 years. For clarity, the figure does not show the distribution of natural debris, although these materials exhibited the same 

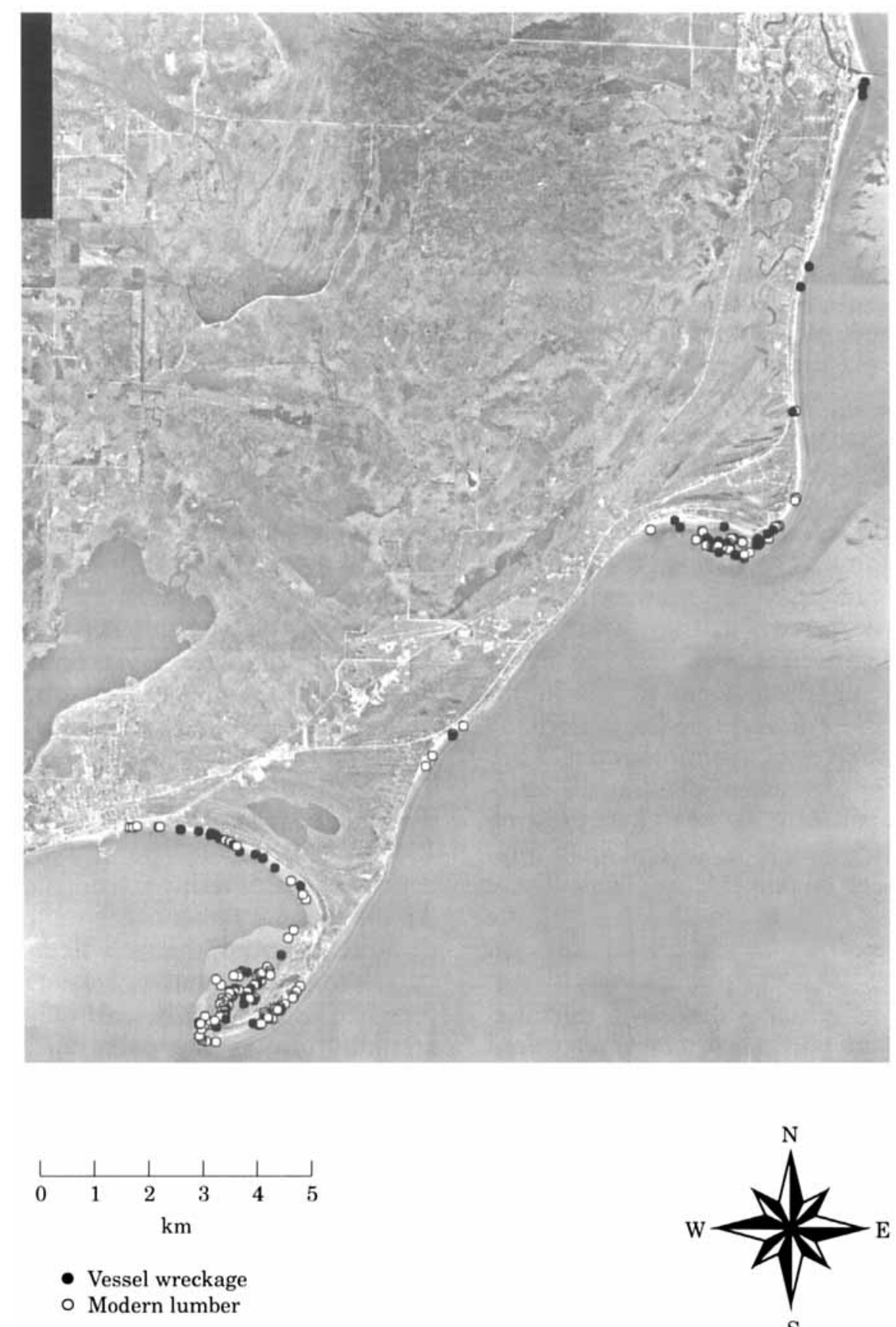

- Vessel wreckage

- Modern lumber

Figure 4. Distribution of vessel debris and modern timber along the Au Sable shore area of western Lake Huron, recorded during survey, May 2001. Background satellite coverage is photo-mosaic produced from USGS digital ortho-quads (DOQ), 1993.

pattern of occurrence. Regardless of age or source, debris is not distributed evenly over the region, but is strongly concentrated in major debris fields in the vicinity of the two recurved spits. Since free-floating wreckage from a broken vessel, like any other debris, tends to accumulate in such areas, the spatial association of wreckage and artefacts within these locations will have no necessary relationship to the original source of the materials.

A closer look at one such debris trap at Au Sable Point clearly illustrates this effect. On the inner side of the Au Sable Point spit, and immediately opposite the site of the previously 
Table 3. Portable artefacts from the Au Sable Point debris trap

\begin{tabular}{lc}
\hline Object & Dating range \\
\hline Nu-Grape Soda Bottle & $1922-1946$ \\
Cork Stopper Olive Bottle & $1900-1917$ \\
Coke Bottle, 6 oz. Patent D Type & $1931-1951$ \\
Coke Bottle, 6 oz. Patent D Type & $1931-1951$ \\
Coke Bottle, 26 oz. & $1951-1965(?)$ \\
Wood Caulking Mallet & Common late 19th century \\
Coal (abundant, large unweathered chunks) & $1901 ?$ \\
Fishing lures, Monofilament line, Lumber, Aluminum beer can, & Modern \\
Plastic soda bottles & \\
\hline
\end{tabular}

described keel and keelson assembly, both scouring and redeposition was occurring. Water action on the inside of the recurved spit produced a small area of relatively deeper water, from which most of the lake sand had been transported, leaving an immobile substrate of lake clay and gravel. In this zone, several pieces of vessel wreckage, deriving from more than one vessel, were observed. They included a $10 \times 2 \mathrm{~m}$ segment of planking, a series of frames still in positional relationship suggesting they were deposited as a unit, several spar fragments and a number of portable artefacts. These materials were first recorded in 1998 and by the spring of 2000 were entirely buried beneath $\mathrm{Au}$ Sable Point.

The concentrating effect of this environment is well illustrated by the portable artefacts recovered (Table 3). It should be noted, however, that this list is not a complete representation of the portable artefacts present. Almost immediately on exposure, the site was overrun by looters who, using diving gear, dredge hooks, and jet skis carted away a large, but unrecorded, portion of the site collection. Table 3 lists all the recorded items and their associated date. What is immediately obvious from this table is that there are materials of widely differing ages that have come to rest on the same depositional surface along with the vessel wreckage. Several of these items might be associated with one or more of the $\mathrm{Au}$ Sable Point wrecks, the vessel fragments and caulking mallet being the least ambiguous. Three of the soda bottles date from within a span that is consistent with the Langell Boys wreck, while the olive bottle predates the Langell Boys wreck by more than 15 years but overlaps with the wreck of the Baltimore above. Much of the coal found in the area is locally attributed to the Baltimore.
To these historic artefacts can be added modern fishing lures, lumber, and aluminium beer cans.

Archaeologically, this deposit, which currently is sealed again beneath Au Sable Point, provides two points of interest. The obvious one is that items found together in a single deposit need not derive from the same event, nor be of similar age. This is the deflating and concentrating effect of a dynamic near-shore environment (Murphy, 1990: 15-16). The second point relates back to the deposition of differing portions of broken vessels. All the vessel fragments encountered in this debris trap are portions that are likely to have drifted away from an initial wreck-site. As such, their presence in the debris trap may be every bit as serendipitous as the occurrence of any of the portable artefacts. In fact, it appears that at least some of these vessel fragments may relate to the nearby keel assembly and thus have moved only a short distance from the apparent wreck-site. On the other hand, since the vessel fragments do not derive from a single vessel, some portion of the wreck assemblage must derive from a more distant location.

There is a possible parallel here between the concept of a 'ship trap', which has evolved from the idea of a particularly hazardous locality for ships (Throckmorton, 1964: 51-61) to localities where shipwrecks are concentrated (Gould, 2000: 82-91), and the 'debris traps' which are observed in Lake Huron. Probably in most instances where clusters of intact vessels are encountered, it is reasonable to search for conditions that would have resulted in repeated wrecks in the locality, but for deep-water wrecks in more open waters, the possibility of natural processes producing a concentration of vessels might also be considered. 
A third variety of post-depositional alteration also relates to the movement of large vessel segments, although at a time far removed from the initial wreck. In December 1994, a large panel of intact vessel planking $(12 \times 3 \mathrm{~m})$ was observed, moving just below the surface of Lake Huron. Over the next 6 months, the fragment was drawn and photographed by local residents as it worked its way along the shore, damaging several small boat docks in the process. Eventually the fragment was dragged ashore, cut up, and burned to prevent further property damage. In May 2000, a fragment of this original panel was relocated on a private beach. The specimen was identified from the earlier photographs and the saw marks at both ends of the fragment were clearly visible. The property owner later confirmed the identification of the fragment and its source. In this case, a large segment of an unidentified schooner, presumably wrecked more than a century earlier, was freed from the bottom and retained sufficient buoyancy to migrate with the current an unknown distance, then to be intentionally scattered, scavenged, and relocated during archaeological survey.

Despite the many confounding influences affecting the distribution and deposition of scattered wreckage, there are systematic elements that can assist archaeological interpretation. For example, once debris breaks free of the stranded vessel and begins to drift, it will drift in the direction of the prevailing winds and currents until it ultimately becomes stuck in one of these debris traps. Even through successive cycles of deposition and release, the debris will continue to move following this directional pattern. In the $\mathrm{Au}$ Sable Shores region, the prevailing direction of drift generally coincides with the long shore current, which transports debris in a north to south direction. As such, it is unlikely that debris trapped on $\mathrm{Au}$ Sable Point would derive from wrecks located south of this point. Such general patterns, of course, are subject to specific local conditions. For example, in Saginaw Bay, the combination of current and easterly winds can rotate debris and wreckage north along the shore of the 'Thumb' and then back west across the bay. Given this local circulation system, it was not uncommon for the debris from wrecks at Point aux Barques on the east side of Lake Huron to appear in Tawas Bay. This was the case with the schooner Table Rock in 1872, which was lost from its tow near Point aux Barques and went ashore on Tawas Point (Iosco County Gazette, 2 Oct., 1872).

\section{Discussion}

Beyond their obvious cautionary value, these cases highlight systematic elements in the depositional and post-depositional processes at work on scattered wreck-sites. In many of these instances, from the Advent photograph to the case just cited, large panels of planking are broken off and move as a unit. In these instances, the interior or exterior planking, or both, remains attached to the associated frames, and survives as large flat pieces of timber. These panels seem most often to derive from the central portion of the vessel (as opposed to the fore or aft sections) and to represent the upper portion of the ship's side and rail, above the turn of the bilge. This pattern of breakup makes sense both in terms of the structure of a wooden vessel, and in terms of where the breaking force would be exerted to the side of a stranded vessel (Labadie, 1989: 126).

The structure and shape of these panels may also partially explain their mobility. The panels have a very large surface area on which wind and current may exert force. This, coupled with residual buoyancy, would seem to provide the means for the panels to be moved along in the water column. Clearly, there is a necessary relationship between the size and weight of the panel and the amount of energy in the lake environment that is needed to produce movement. By contrast, the more complex, three-dimensional geometry of the fore and aft portions of a vessel would present less surface and more drag to counteract the forces for movement. As such, fore and aft segments should be less likely to move in the water after their initial deposition and loss of buoyancy. If these portions break up further, they will predictably separate into the heavier axial elements, which will tend to remain in place, and more mobile and buoyant planking, which may resume drifting.

While a realistic assessment of the deposition and post-depositional processes acting on shallow water wrecks might lead one to conclude that nothing useful can be done with these sites, that assessment is far from accurate. Instead, these factors simply force the nautical archaeologist to abandon Pompeii and to adopt the normal conceptual tools that terrestrial archaeologists apply to the understanding of complex archaeological deposits. Even with badly scattered wrecks, nautical archaeologists still enjoy an important advantage over their land-based counterparts, and that derives from the planned structure of the 
vessel itself. Indeed, the very complexity and redundancy of vessel construction and function can be the critical key for untangling the complexities of deposition and post-deposition. With knowledge of deposition and post-depositional processes, one can use the canons of vessel construction to determine whether, for example, various pieces of wreckage can be attributable to the same, similar, or different vessels. This attribution may be based on the style or period of construction, the type of vessel and the overall size or capacity. All of this information is encoded in the construction and dimensions of the vessel itself, and requires only accurate observation and the correct identification of the vessel portion being examined. In essence, the nautical archaeologist adopts a kind of forensic analysis of vessel debris.

The present research also stresses the importance of understanding the depositional environment as another line of 'forensic' evidence. In the $\mathrm{Au}$ Sable Shores study area, for example, the prevailing long shore current moves wreckage and other materials in a southerly direction. Therefore, if the approximate location of the stranding is known or can be inferred from historical records, it will normally be possible to eliminate fragments of vessels that are discovered north of the wreck-site, while remembering of course, that historical records have their own limitations on accuracy. Such information, which can often be found formalized in general environmental models of lake circulation and climate, can be coupled with historic meteorological observations at times relevant to known wrecks to form concrete predictions of wreck location and debris scattering. ${ }^{[4]}$

Since scattered wrecks and wreck localities can yield important historical and archaeological information, it is necessary to reassess the kinds of management and protection such sites receive. In principle, wrecks of a scattered character are afforded the same legal protection as intact wrecks. In practice, however, and given limited resources, only intact wrecks receive any significant research and preservation effort. Such a policy, while perhaps understandable, creates a serious obstacle to the historical understanding of the nautical past, since it effectively eliminates an entire class of vessel loss from research consideration. Current efforts within the Great Lakes region to create underwater preserves, which are defined regionally and contain a variety of wreck types, represent one important means by which the full variety of wrecks can be examined and protected.

\section{Conclusions}

While many factors work to disperse and intermix the wreckage from stranded wooden ships, the documentation of the depositional and postdepositional processes provides the bedrock on which an archaeological study of scattered wrecksites can be based. An understanding of how these sites are formed and modified will not only enhance their research potential, but will also enable culture resource managers to better evaluate scattered wreck-sites and justify their protection.

\section{Acknowledgements}

The Au Sable Shores research has benefited from the advice and steadfast support of John R. Halsey (State Archaeologist) and Kenneth Vrana (Center for Maritime and Underwater Resource Management). The historical advice of Dave Swayze and Neal Thornton is gratefully recognized. It is perhaps also fitting to acknowledge the unnamed looters, whose plundering of a newly exposed wreck provided the impetus for this study of western Lake Huron's scattered wrecks.

\section{Notes}

[1] For example, see Gould, 2000; Hulse, 1981; McCarthy, 2000; Muckleroy, 1978; Murphy, 1990; Quinn et al., 2002; Ward et al., 1999.

[2] The Au Sable Shores project is based in the Great Lakes Division of the Museum of Anthropology, University of Michigan. The research described was funded in part by the Coastal Management Program of the Michigan Department of Environmental Quality (DEQ), Project \#01-309-13.

[3] There is some uncertainty whether the wreckage described derives from the D. M. Wilson or from the schooner John Shaw which ran aground and broke up on 13 November, 1894 near Greenbush, Michigan, roughly $45 \mathrm{~km}$ north of Tawas Bay. In either case, the wreckage observed at Tawas Bay had scattered quickly and over a considerable distance.

[4] See Forsythe et al., 2000 for a comparable case in Ireland.

[5] This is maintained as an online database at http://greatlakeshistory.homestead.com/home.html 


\section{Bibliography}

Annual Reports of the United States Life Saving Service, 1876-1914. Washington.

Bass, G., 1983, A plea for historical particularism in nautical archaeology. In R. Gould (Ed.), Shipwreck Anthropology, 91-104. Albuquerque.

Binford, L., 1981, Behavioral archaeology and the 'Pompeii premise'. Journal of Anthropological Research, 37: $195-208$.

Clarke, D., 1973, Archaeology: the loss of innocence. Antiquity, XLVII: 6-18.

Conlin, D., 1998, Ship evolution, ship 'ecology' and the 'masked value hypothesis'. IJNA, 27: 3-15.

Dumas, F., 1972, Ancient wrecks. In UNESCO. Underwater Archaeology, a Nascent Discipline, 27-34. Paris.

Ferris, P., 1999, The Shipwrecked Baltimore, Forest Park, Illinois.

Fontenoy, P., 1998, A discussion of maritime archaeology. In L. Babits \& H. van Tilburg (Eds), Maritime Archaeology: A Reader of Substantive and Theoretical Contributions, 47-52. New York.

Forsythe, W., Breen, C., Callaghan, C. \& McConkey, R., 2000, Historic storms and shipwrecks in Ireland: a preliminary survey of severe synoptic conditions as a causal factor in underwater archaeology. IJNA, 29: 247-259.

Gibbs, J., 1986, Peril at Sea: A Photographic Study of Shipwrecks in the Pacific. West Chester, Pa.

Gould, R., 2000, Archaeology and the Social History of Ships. Cambridge.

Hulse, C., 1981, A Spatial Analysis of Lake Superior Shipwrecks: A Study in the Formation Processes of the Archaeological Record. PhD. Dissertation, Michigan State University, East Lansing.

Labadie, C. P., 1989, Submerged Cultural Resources Study: Pictured Rocks National Lakeshore. Southwestern Cultural Resources Center Professional Papers, 22. Santa Fe.

LaValle, P., Brocks, A. \& Lakhan, V. C., 1999, Zebra mussel wastes and concentrations of heavy metals on shipwrecks in western Lake Erie. Journal of Great Lakes Research, 25: 330-338.

Mansfield, J., 1899, History of the Great Lakes (reprinted 1972). Cleveland.

Martin, C. \& Long, A., 1975, The use of explosives on the Adelaar site. IJNA, 4: 345-352.

McCarthy, M., 1996, Ship fastening: a preliminary study revisited, IJNA 25: 177-206.

McCarthy, M., 2000, Iron and Steamship Archaeology: Success and Failure on the SS Xantho. New York.

Meadows, G., 2000, Tawas Area Sediment Budget Study, Report OEL-0002. University of Michigan Ocean Engineering Laboratory, Ann Arbor.

Muckelroy, K., 1975, A systematic approach to the investigation of scattered wreck-sites. IJNA, 4: $173-190$.

Muckelroy, K., 1978, Maritime Archaeology. Cambridge.

Murphy, L., 1990, 8SL17: Natural Site-Formation Processes of a Multicomponent Underwater Site in Florida. Southwest Cultural Resources Center Professional Papers, 39. Santa Fe.

Murphy, L., 1993, Windjammer site (FOJE 003). In L. Murphy (Ed.), Dry Tortugas National Park: Submerged Cultural Resources Assessment. Southwest Cultural Resources Center Professional Papers, 45: 245-272.

Murphy, L. \& Jonsson, R., 1993, Environmental factors affecting vessel casualties and site preservation. In L. Murphy (Ed.), Dry Tortugas National Park: Submerged Cultural Resources Assessment. Southwest Cultural Resources Center Professional Papers, 45: 97-110. Santa Fe.

Ottawa Point Life Saving Station Log. United States Life Saving Service, Records of the United States Coast Guard [USCG], NARG 26.

Quinn, R., Breen, C., Forsythe, W., Barton, K., Rooney, S. \& O'Hara, D., 2002, Integrated geophysical surveys of the French frigate La Surveillante (1797), Bantry Bay, Co. Cork, Ireland. Journal of Archaeological Science, 29: 413-422.

Reedy, J., 1991, Field procedures developed for a scattered, deeply buried site in a high energy location: the Whydah (WLF-HA-1), Cape Cod, Massachusetts, USA. IJNA, 20: 53-58.

Schiffer, M., 1987, Formation Processes of the Archaeological Record. Albuquerque.

Souza, D., 1993. East Key Construction Wreck (FOJE 011) 1990 investigations. In L. Murphy (Ed.), Dry Tortugas National Park: Submerged Cultural Resources Assessment Southwest Cultural Resources Centre Professional Papers, 45: $303-324$.

Souza, D., 1998, The Persistence of Sail in the Age of Steam. New York.

Swayze, D., 2001, The Great Lakes Shipwreck File: Total Losses of Great Lakes Ships, 1679-2001. Lake Isabella, Michigan ${ }^{[3]}$. Thompson, M., 2000, Graveyard of the Lakes. Detroit.

Throckmorton, P., 1964, The Lost Ships. Boston.

Tomalin, D., Simpson, P. \& Bingeman, J., 2000, Excavation versus sustainability in situ: A conclusion on 25 years of archaeological investigations at Goose Rock, a designated historic wreck-site at Needles, Isle of Wight, England. IJNA, 29: 3-42.

van Tilburg, H., 1994, Zero-visibility diving on the Maple Leaf: tricks of the trade. IJNA, 23: 315-318.

Wadsworth, J., 1975, Transport Mechanisms Operating on a Recurved Spit, Tawas Point, Michigan. MS Thesis, Dept of Geology, University of Michigan, Ann Arbor.

Ward, I., Larcombe, P. \& Veth, P., 1999, A new process-based model for wreck-site formation. Journal of Archaeological Science, 26: 561-570. 